\title{
UN LITIGIO INDIO EN EL SIGLO XVI. EL CÓDICE COZCATZIN
}

\author{
Ana Rita Valero \\ Universidad Nacional Autónoma de México. México D.F. México.
}

Los dramáticos acontecimientos que se dan en México hacia el primer cuarto del siglo XVI, tras la victoria española, inician una serie de cambios profundos cuyas repercusiones afectan a casi todos los ámbitos del quehacer autóctono. Desde entonces, una gran parte de la cultura indígena se va a ver desplazada por formas culturales nuevas, unas traídas de Europa, otras gestadas localmente como respuesta a la nueva circunstancia.

Dentro de este escenario de gran transformación, la propiedad indígena experimenta un sinnúmero de alteraciones que darán como resultado final un fuerte quebranto del antiguo patrimonio de los indios, de magnitud tal que, en dos siglos éstos sufren la pérdida de la mayor parte de su herencia inmobiliaria'.

Es necesario señalar empero, que ese infortunado desenlace ocurre a pesar de que la legislación indiana se diseńó desde el principio con un sentido de justicia encaminado siempre a la protección del indio ${ }^{2}$.

Desde 1512, cuando se emiten las Leyes de Burgos, casi diez años antes de la calda de México, éstas reconocen con claridad la legitimidad de la propiedad del hombre americano y la ratifican formalmente ${ }^{3}$; aunque en la realidad muchas veces se transgredieron, como ha sucedido tal vez con toda ley en la historia del hombre.

Por ello, a pesar del justo contenido de los códigos indianos, el arranque de la vida cotidiana en las tierras recién conquistadas, experimentó con- 
tinuas fricciones, enfrentamientos y contrariedades, sobre todo en ciertos campos de especial conflicto como fue el de la propiedad inmobiliaria.

Tanto las fuentes coloniales como los investigadores contemporáneos parecen aceptar que la posesión de la tierra en el México prehispánico estuvo organizada en torno a una estructura compleja que al momento del contacto englobaría a varias categorías. Aparentemente hubo superficies de tierra dedicadas al sostenimiento de los templos (teocalli), otras más que mantendrían al aparato gubernamental (tecpantlalli), otras designadas para el goce de la nobleza (pillali, tecubtlalli) y las tierras que usufructuaban las comunidades (calpullali) 4 .

Pero una vez terminada la conquista y ante la decisión de los españoles de avecindarse allí, esa compleja estructura inmobiliaria sufre modificaciones sustanciales en todos sus órdenes. Por la erradicación de la antigua religión dejan de existir totalmente las tierras de los templos, y por razones similares las del gobierno, mientras que las propiedades de las comunidades y las de la nobleza, aunque teóricamente se conservan, resienten cambios importantes.

Hubo múltiples alteraciones de fondo y de forma; las primeras causadas por la introducción de un concepto diferente del dominio de la tierra; las segundas derivadas de aquel pero también surgidas al implantar en el mundo indígena otras costumbres, distintas tecnologías y otros pensamientos políticos y económicos. Se sufrió un dislocamiento general que dio como resultado la pérdida casi total de la riqueza indígena, más aguda en ciertas zonas de especial conflicto como lo fue la Cuenca de México, donde se concentró una intensa actividad colonial.

Fueron años en los que se vivieron cambios muy intensos, que revolucionaron todo un universo humano, afectando a múltiples áreas de la actividad autóctona. Tal vez por ello no extrañe que haya sido también un escenario de grandes pleitos, pleitos por tierras, pleitos por aguas, pleitos por dineros y no solo, como sería lógico suponer, entre conquistados y conquistadores que en este caso eran indios y españoles, sino peor aún, al interior de la República de Indios, en donde también se discutió y se discrepó y se peleó, en ocasiones con mayor vigor aún 5 .

Viene en aquel entonces un verdadero raudal de litigios de juicios y querellas; fue el famoso "pleitismo indígena" del que habla impresionado Zorita ${ }^{6}$, pleitismo generado precisamente como consecuencia directa de ese traumático momento.

Fue una etapa que exigía imperiosamente una eficaz impartición de justicia, que requería con urgencia un orden jurídico que pudiera aclarar dudas y disipar imprecisiones, que solventara las fuertes diferencias que 
enfrentaban a unos y otros en los diversos negocios, en la relaciones laborales y sobre todo, en el conflictivo asunto de la tenencia de la tierra que paradójicamente se daba en los inmensos territorios de la Nueva España.

La Corona respondió a esta ingente necesidad de administración jurídica diseñando un derecho que originalmente se derivaba sólo del castellano, pero que poco a poco fue tomando también en consideración las necesidades locales y las preferencias particulares de aquel extraño y nuevo mundo; así la legislación real, escuchando con apertura los problemas vivos de la colonia va incluyendo un buen número de ordenanzas y autos acordados dictados tanto por la Audiencia como por los distintos virreyes. Es decir, se estaba gestando un original derecho mexicano nacido allí y alimentado básicamente por el derecho castellano pero completado además con la sabiduría de la vida diaria, con la riqueza de la cotidianeidad, dando a efecto a la costumbre como una de las fuentes del Derecho?.

Y es precisamente durante ese crítico tiempo de "intensidad jurídica" y de fuerte actividad procesal, cuando surgen los códices coloniales que juegan un papel de primordial importancia en el contexto novohispano.

Los códices fueron un factor de comunicación entre dos mundos diferentes, fueron un punto de enlace dentro de un escenario controvertido, tenso, incomprensible; se trata de una literatura sui generis que nace en ese momento para responder a la necesidad de establecer un conducto entre dos partes contendientes que no lograban entenderse.

Así, mediante los códices las partes querellantes encuentran por fin una forma de expresión que entendieran ambas, un medio de comunicación que respondiera a las estructuras tan especiales de aquel entonces, que sirviera para lidiar aquella peculiar problemática del México recién conquistado, en donde se enfrentaban jurídicamente indios contra españoles, pero también indios contra indios, sólo que ahora bajo una nueva autoridad, la virreinal. En estas circunstancias, urgla diseñar un conducto eficiente para ser usado dentro del nuevo derecho indiano que se estaba estrenando allí y que intentaba concertar y poder armonizar los intereses discrepantes de dos comunidades dispares.

Hoy se conocen casi medio millar de códices coloniales producidos durante el siglo $\mathrm{XVI}^{8}$; son documentos que manejan diferentes asuntos que respondieron en su momento a las necesidades concretas de la vida diaria, sin embargo, dentro de la amplia variedad temática sobresalen en número aquellos que provienen de la Cuenca de México, lo cual no extraña, si recordamos que es precisamente la capital del virreinato el centro político y económico que rige la vida colonial. 
Y de la región llamada Tlatelolco- Santa Isabel Tola-Ixhuatepec, en el norte de la Cuenca, procede el documento conocido hoy como el Códice Cozcatzin; es una pieza redactada hacia el último cuarto del siglo XVI, ejecutada sobre papel europeo, con especial elegancia. Se trata de un célebre litigio formulado en aquellos años para acusar al gobernador de Tlatelolco por haberse apropiado las tierras de cincuenta y cinco familias indígenas de la Ciudad de México.

Actúan en este juicio tres protagonistas principales: la parte "actora", la parte "demandada" y las autoridades virreinales formadas tanto por funcionarios españoles como también por indios, éstos en los mandos medios y aquellos controlando las esferas superiores.

I.-LA PARTE ACTORA estuvo integrada por las familias de los despojados, quienes curiosamente no especifican en el escrito su calidad social por lo que se podría pensar en que formaron parte del estado llano o de los "macehuales", ya que ni siquiera se les da el tratamiento de "don" a lo largo del documento.

Sin embargo, haciendo un análisis pictográfico del códice en donde se representa a cada jefe de familia sentado en un pequeño asiento ${ }^{10} \mathrm{y}$ envuelto en una tilma $a^{11}$ que parece ser de algodón, se podría deducir una posible categoría de rango, ya que el uso de ambos elementos, asiento y algodón se restringía a la nobleza.

Pero sobre todo, atendiendo al argumento de que en el códice se exhiben cincuenta y cinco títulos de propiedad cuya legitimidad se basa precisamente en el histórico reparto hecho por Itzcoátl, el cuarto rey de Tenochtitlán en 1439 a sus principales se incluye de facto la antigua jerarquía de los demandantes ${ }^{12}$.

Ellos alegan haber usufructuado y poseído las tierras en cuestión a partir de 1439, lo cual indica una propiedad continua de ciento diez y ocho años en las mismas manos, y aunque entre los demandantes hay un caso firmado por un tataranieto, la mayoría de ellos (veinte y dos) se identifican como bisnietos de los dueños originales, es decir, que se trata de la cuarta generación que después de ciento treinta y tres años exigen sus derechos como legítimos herederos. En once casos firman la demanda los nietos de los propietarios o sea la tercera generación, y los restantes doce descontentos hablan de "padres y parientes" o incluso usan términos más vagos como "parientes más cercanos". 
Si las declaraciones contenidas en el códice fueron verídicas, quiere decir que las familias demandantes disfrutaron con todo derecho de aquellas propiedades que legítimamente les correspondían de antaño.

II.-LA PARTE DEMANDADA fue don Diego de Mendoza Austria Moctezuma Huitznahuatlailotlac ${ }^{13}$ Imayantzin ${ }^{14}$, una figura que ilustra claramente el momento tan controvertido que le tocó vivir.

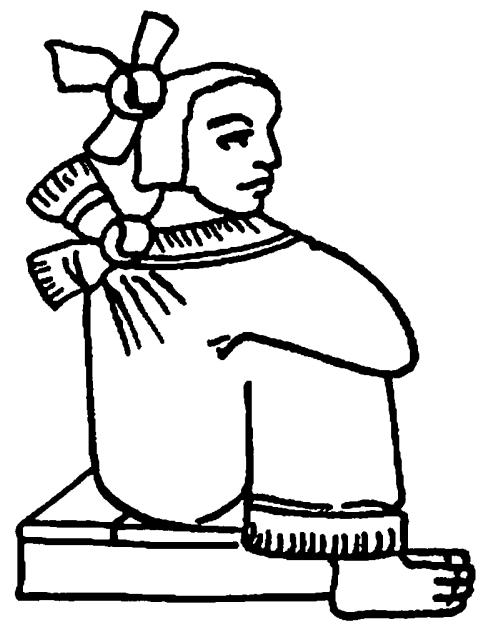

Lámina 1.- Imagen de uno de los propietarios que demandaron al gobernador de Tlatelolco, Don Diego de Mendoza Austria Moctezuma.

El declara ser hijo de Cuauhtémoc, último Tlatoani de México, y de una "hija lexítima del emperador Moctezuma" is, lo cual lo hace hijo y nieto de emperadores, es decir, una familia cuyo linaje se coloca dentro de la más alta nobleza mexica. Don Diego, casado con dońa Magdalena Cacuahpitzáhuac, gobierna Tlatelolco entre los años de 1549 y 1562 y aunque la Crónica Mexicáyotl lo hace hijo de un príncipe tlatelolca llamado Zayoltzin ${ }^{16}$, su hijo don Balthasar de Mendoza Austria Moctezuma continúa un importante litigio reclamando su ascendencia directamente de Cuauhtémoc ${ }^{17}$.

A partir de la organización del nuevo reino, tras la caída de México, los gobernantes indígenas siguieron en sus cargos con la intención de preservar la estructura política autóctona como instrumento de las autoridades virreinales. La postura de la Corona española con respecto a los nobles indígenas siguió una línea de respeto y reconocimiento a las antiguas jerarquías; considerábase que si el pueblo les había rendido vasallaje, deberían continuar en su antiguo nivel, conservando sus fueros y privilegios; incluso se pensaba que a los indios correspondían los mismos honores que a los nobles de Europa.

Así, se despachan cédulas en el tenor siguiente "Hay distinción entre los indios y mestizos o como descendientes de los Indios principales que se llaman Caziques...a quienes se les debe preeminencia y honores...como si fueran Hijo-dalgos de Castilla ${ }^{18}$.

Siguiendo la misma línea, Carlos V dicta una Cédula Real en Sevilla el 14 de abril de 1523 reconociendo a don Diego como descendiente directo 
Ana Rita Valero

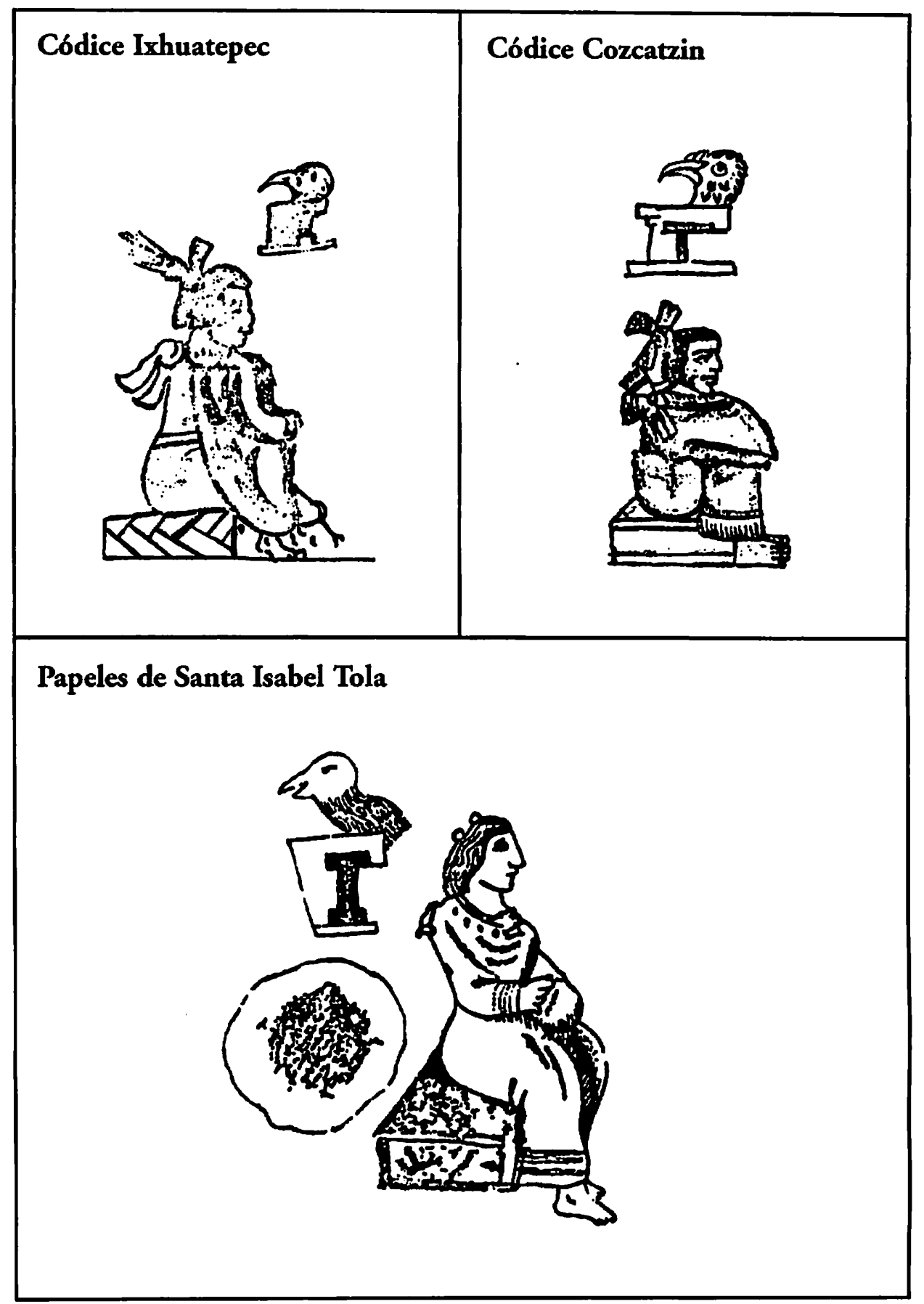

Ldmina 2.-Tres imágenes similares de propietarios en tres diferentes códices.

126 
del emperador Moctezuma e hijo de Cuauhtémoc, otorgándole el cacicazgo de Axacuba, Xochimilco y Santiago Tlatelolco; así, el reconfirma la propiedad de las tierras de su cacicazgo y señorío que eran las llamadas del "rincón de don Diego" y que comprendían la laguna de Ecatepec, San Cristóbal, Tacuba, Chontalpa, Mextitlán, Juchipila, Jalisco, Chalco, Atenco, Coscatlán, Temamatla, Teposcopula, Ayacapán y Tascamoyo así como todas las de Chilapa ${ }^{19} y$ además recibe la merced de gobernar perpetuamente los pueblos de Santiago Tlatelolco, Axacuba y Chilapa ${ }^{20}$.

Sin embargo, a los seis años de su gubernatura, don Diego sufre un juicio de residencia, lo cual permite pensar en la presencia de ciertas inquietudes respecto a la probidad del mandatario. Así las cosas, don Diego es el demandado en el Códice Cozcatzin, en donde todos los demandantes concuerdan en señalarlo como el que usurpa ilegalmente una importante cantidad de tierras.

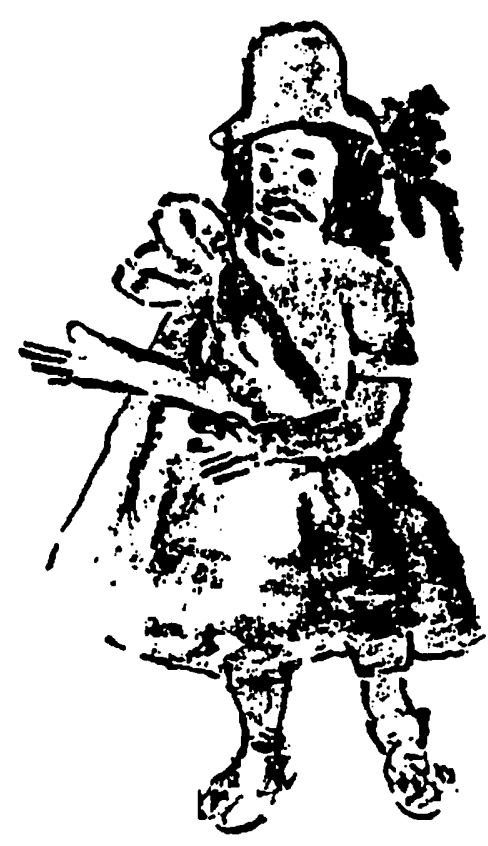

Lámina 3.-La parte demandada, don Diego de Mendoza en el Codice Garcia Granados.

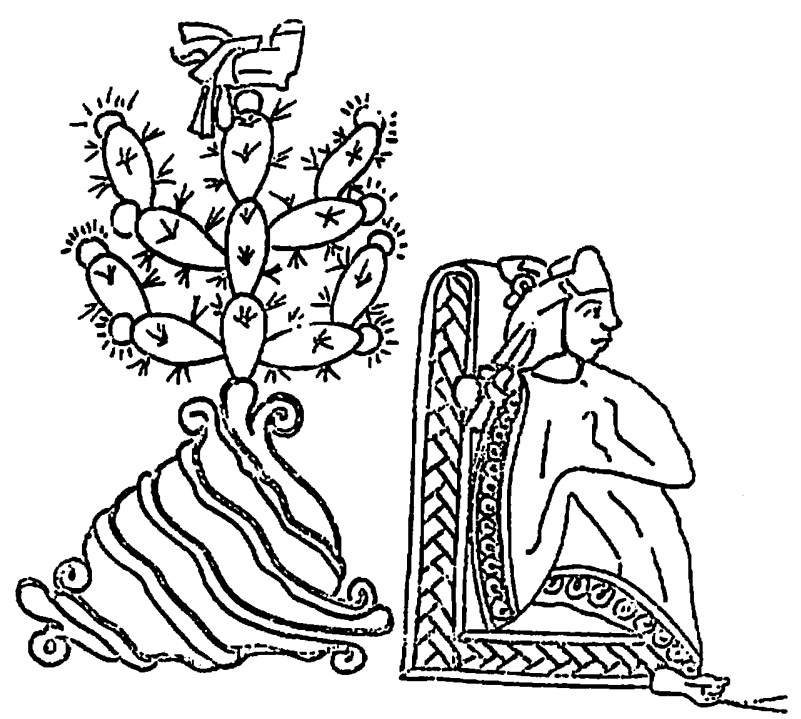

Ldmina 4.-Moctezuma Xocoyotzin, último Señor de México, abuelo de Don Diego de Mendoza. 


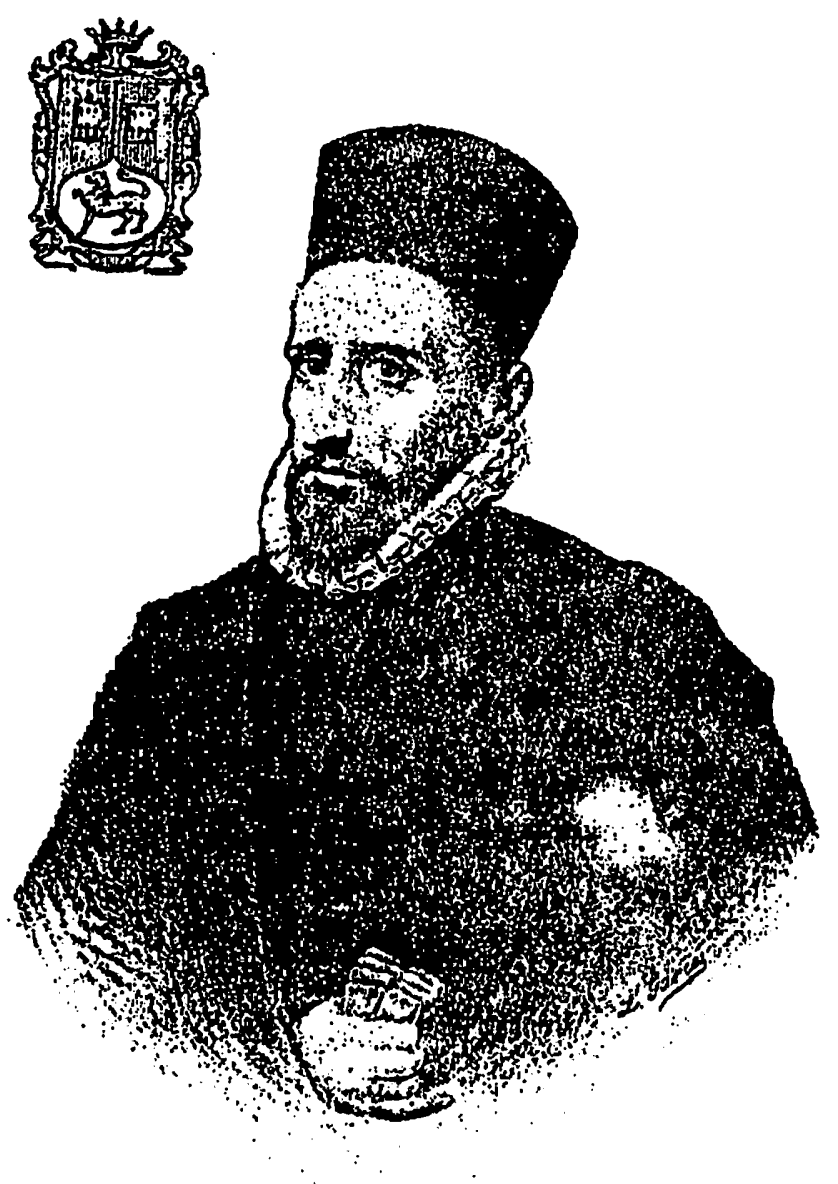

D. Martin, Enrriquez ab Mlmansa fiProrrex et Dux Generalis Año 1;'68.

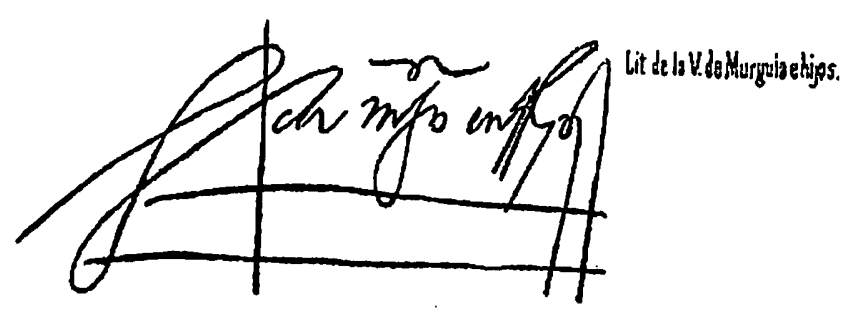

Lámina 5.-Don Martín Enriquez de Almansa, virrey de Nueva España durante el proceso. 
III.-LAS AUTORIDADES. Un papel importante dentro del litigio recayó en las autoridades judiciales de aquel entonces, representadas en primera instancia por un funcionario indígena llamado don Joan Luis Cozcatzin, quien ese año fungía como alcalde ordinario del barrio de San Sebastián, uno de los cuatro que formaron la jurisdicción de la ciudad de México.

Siguiendo la organización colonial, los alcaldes se ocuparon precisamente de las tareas judiciales y eran "cadañeros", es decir que se elegían por un año ${ }^{21}$, durante el cual usaban su bastón borlado como símbolo de autoridad para impartir justicia ${ }^{22}$. Es posible que el señor Cozcatzin haya sido el especialista que elabora la demanda y estructura todo el juicio en contra del gobernador.

Los procedimientos judiciales de aquel entonces permitían a los indios presentarse ante el virrey para solicitar justicia; en

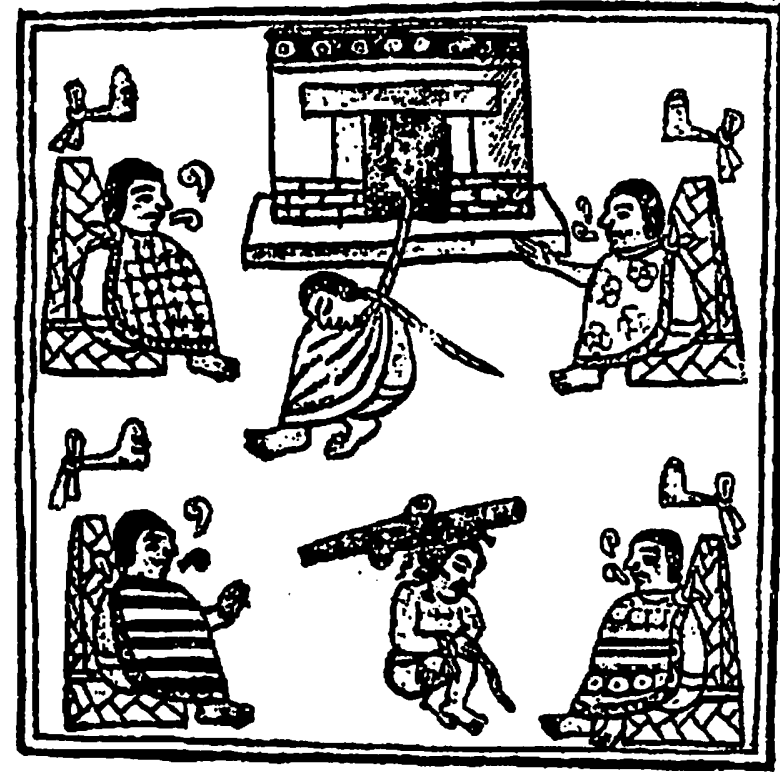

Lamina 6. - Libro Octavo, folio 26 del Códice Florentino, en donde aparece la "sala de la judicatura", espacio dedicado a la imparticion de justicia en el México antiguo. ese tiempo fungía como cabeza del virreinato don Martín Enriquez de Almansa, quien normalmente después de oír a los inconformes, despachaba de inmediato el asunto. Sin embargo, en casos más complicados como parece haber sido el presente, se requería de una investigación más profunda, motivo por el cual seguramente se tuvo que manufacturar el documento conocido hoy como Códice Cozcatzin. En este proceso quizá se exigió a los demandantes exhibir ciertas pruebas documentales que reforzaran los argumentos emitidos en el juicio y que comprobaran sus pretensiones como supuestos propietarios.

El demandar a un alto funcionario parece haber sido una práctica muy restringida en las antiguas sociedades prehispánicas; este tipo de inconformidad seguramente llegó con la costumbre española y a partir de la administración de la Segunda Audiencia ${ }^{23}$, como se puede comprobar en el presente 
documento. Pero además en este pleito se estaba acusando a la máxima autoridad del gobierno indígena, lo cual implicaba tal vez mayores exigencias.

IV.-LA MATERIA DEL LITIGIO. El despojo se realizó sobre un conjunto de cincuenta y cinco predios agrícolas, la mayor parte de los cuales tenían "400 brazas de largo por 20 de ancho", lo cual arrojaría un total de 8,000 brazas de superficie, sin embargo se habla también de parcelas de 200 brazas por 20 de ancho y otras familias mencionan solamente "las brazas susodichas", tal vez indicando la medida de 400 por 20; una más habla de 1,200 brazas y tres mencionan 20 por 10 . El resto de los demandantes no indica con precisión las medidas de sus terrenos, pero el escrito inicial menciona que Itzcoátl, repartió "por iguales partes" y da dos tipos de superficies, la de 8000 brazas y la de 4000 . Suponiendo que la mitad de los demandantes hubieran recibido las famosas 8,000 y la otra mitad 4,000, habría:

$$
\begin{aligned}
4,000 \times 8,000 & =184,000 \text { brazas } \\
22 \times 4,000 & =84,000 \text { brazas } \\
\text { Total } & 242,000 \text { brazas }
\end{aligned}
$$

El realizar una equivalencia a sistemas de medición modernos es siempre un riesgo, ya que los métodos indígenas de la época, basados en el cuerpo humano ofrecían múltiples variantes por la diversidad de la anatomía humana. Los diferentes grupos étnicos tuvieron distintas tallas y estaturas; los aztecas por ejemplo, alcanzaban un promedio de 1.62 metros, mientras que los tarascos u otomíes sólo 1.59 metros, lo cual repercutía forzosamente en los sistemas de medición. Si bien, es cierto que el virrey don Antonio de Mendoza impuso una Ordenanza sobre medidas agrarias el 4 de julio de $1536^{25}$ que regulaba las normas al respecto, parece que las brazas se calculaban con distintos criterios; para unos era lo comprendido entre el pie izquierdo y la mano derecha levantada, para otros era de dedo a dedo con los brazos extendidos. De suerte que para determinar las superficies de casas, solares y terrenos en México-Tenochtitlán, se usaron brazas de 1.67, 2.08 y 2.16 metros $^{26}$.

Hoy las tierras del pleito estarían en el pueblo llamado San Juan Ixhuatepec, dentro de la zona conurbada de la ciudad de México, y aunque dicho pueblo pertenece a la jurisdicción del Estado de México, lo cierto es que la mancha urbana de la ciudad lo ha absorbido, integrando a su población a la economía capitalina. 
Ixhuatepec estuvo ligado antiguamente al Señorío de Azcapotzalco, pero tras la caída de éste en el siglo XV, los mexica de Tenochtitlán, comandados por Itzcoátl, se adjudican dichas tierras y las reparten entre sus principales, como se afirma precisamente en el Códice Cozcatzin.

Aproximadamente cien años después, ya en pleno siglo XVI se dice que: "...hicieron junta los principales y determinaron que se construyese una ermita y eligieron por patrón a San Juan Bautista..." ${ }^{27}$; desde entonces hasta hoy el pueblo se ha llamado San Juan Ixhuatepec. Para finales del siglo, dicha ermita se convierte en una iglesia de Mamposteria..." ${ }^{28}$, bajo la jurisdicción de Santiago Tlatelolco, posteriormente se sujeta a la Parroquia de Guadalupe y hoy en día, siendo ella misma Parroquia, depende del Obispado de Tlaltnepantla ${ }^{29}$.

\section{Códice Cozcatzin}
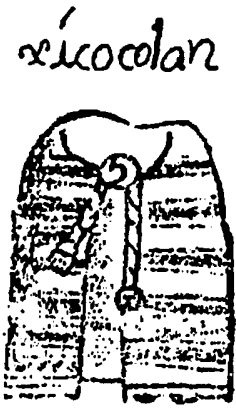

Ldmina 7.-Dos toponimos de las parcelas expropiadas. Xicocolan y Ticoman.

Formular hoy a cuatro

siglos de distancia una opinión correcta sobre la operatividad del nuevo sistema judicial instaurado para regular la vida diaria de Nueva Espana, implicaría ciertos riesgos de imprecisión histórica; en aquella época la riqueza indígena sufrió intensas presiones que la desgastaron y la debilitaron profundamente, proceso que se dio, paradójicamente, ante la presencia de un marco jurídico instituido. En el desarrollo del caso Cozcatzin se podrían contemplar de manera hipotética varias posibilidades:

\section{I.-Mal gobierno}

Que realmente, como se afirma a lo largo del documento haya habido un elemento de injusticia y mal gobierno por parte del mandatario indígena en contra de sus gobernados, situación que no fue extrana en aquel enton$\operatorname{ces}^{30}$, y que de haber existido, lastimaría no sólo la estabilidad patrimonial de los supuestos propietarios, sino peor aún, el equilibrio moral de la comunidad indígena, como lo dijo con gran energía en su momento el oidor Zorita $^{31}$. 
Códice Cozcatzin

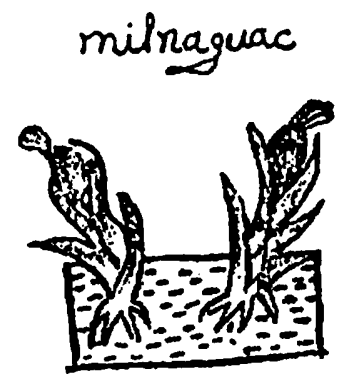

Lámina 8.-Milnabuac y Tomatlan, dos parcelas expropiadas.

\section{Códice Cozcatzin}

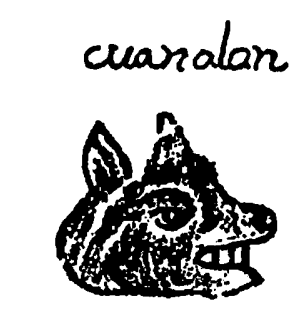

tescacuac

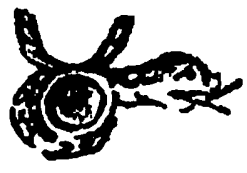

tescacobual?

Lamina 9.-Cuanalan y Tescacoac o Tescacohuatl también entraron en el litigio.
II.-Corrupción.

Que hubiese intereses corruptos a nivel de autoridades medias en la persona del alcalde Cozcatzin, similares a las que públicamente denunció Zorita cuando escribe que <los alcaldes> “...no sirven más que para robar..." y que están "muy ladinos y desenvueltos" ${ }^{32}$. O bien, cuando el padre Las Casas le reporta a Felipe 11 que "...los alcaldes ordinarios han hecho muchos desacatos y desverguenças..." 33; o cuando el doctor Vasco de Puga, hablando del mismo problema, aconseja que "convendría...que les tomaren <residencia> porque algunos de ellos han hecho cosas dignas de castigo" ${ }^{34}$.

\section{III.-Abuso.}

O por el contrario, que los cincuenta y cinco querellantes, valiéndose de la desorientación general de aquel momento y practicando una "nueva inmoralidad" 35 , intentaran lucrar adquiriendo ilegal e infundadamente un número de propiedades que por derecho no les pertenecían; fue una situación que parece haber estado presente en los conflictos interindígenas de ese entonces, se generó una coyuntura en la que se vivieron fuertes luchas por el poder, algunas provocadas por antiguos macehuales anhelando astutamente llegar a una ventajosa posición de nobleza ${ }^{36}$. 


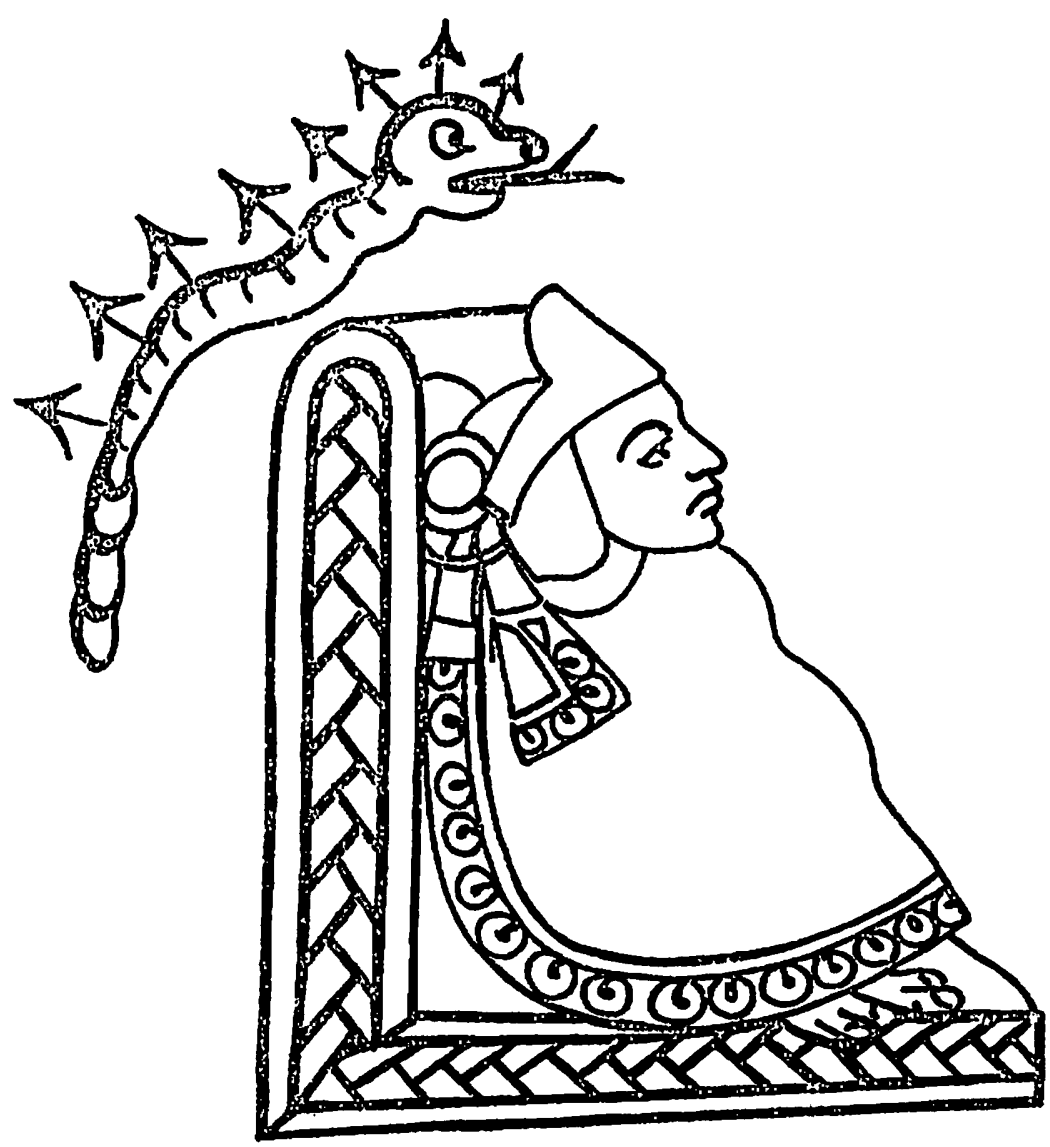

Lámina 10.-Itzcbatl, cuarto rey de Tenochtitlan, quien asigna las tierras afectadas.

Conocer la veracidad de las declaraciones ofrecidas en el Cozcatzin, o la postura de las autoridades en casos con éste, o mejor aún, la sentencia dictada en el juicio, nos daría un panorama más preciso sobre el tan debatido tema de la tierra en aquel controvertido escenario. El pleito que aquí se presenta fue tan sólo uno de los múltiples enfrentamientos que se dieron dentro de la República de Indios como consecuencia del gran reacomodo que en materia de propiedad resultó tras la conquista y que nos describe no sólo los profundos trastornos que vivió la población de aquel entonces, sino también la magnitud de la tarea que significó establecer un nuevo orden, un pensamiento diferente, una nueva manera de resolver la vida diaria en aquella inmensa y Nueva España instalada en México en el siglo XVI. 


\section{NOTAS}

1 Valero, Sánchez de Tagle, Martínez. (en prensa).

2 A este respecto se pueden consultar entre otras las siguientes: Real Cédula de 31 de marzo de 1535; Ley XII dad por el Emperador don Carlos a 24 de mayo y 2 de mayo de 1550; Ley IX de 1560; Real Cédula del 19 de febrero de 1570; Ley VII de 1588; Ley IX de 1594; Ley XVIII de 1642. Son algunos ejemplos de las disposiciones de protección al indio americano. Véase también a Závala, p. 110.

3 "Leyes de Burgos, 1512", en: Vázquez, pp. 191 a 198 y ss. Morales Padrón, p. 309, en donde se comenta como las Leyes de Burgos, al considerar al indio como ser libre y racional, le concedieron, entre otros, los derechos de propiedad.

4 Véase: Durán, Cap, XI; Zorita, pp. 30-35; Clavijero, libro VII, núm. 14 y para la época contemporánea: Caso,; Castillo Farrera, Gibson.

5 Závala, p. 118 y 133; Borah, p. 139; Taylor, 1973, pp. 108-109 y 1987 p. 229.

6 Zorita, pp. 101 y ss.

7 Ventura Belefia "Introducción" p. XXI; Borah, p. 263; Závala, p. 107.

8 Glass, p. 15.

9 Macehuales de macehualli=vasallo, hombre del pueblo, sujeto en: Simeon, p. 244 y Molina, p. $50 \mathrm{v}$.

10 Un tlatotoctli on un icpaltontli que se relacionarla con signo de poder de los antiguos jefes, los sefiores tenían el derecho de usarlos; en s.f.: protector jefe, gobernador, padre, madre, etc. en Simeon, pp. 173, 681 y Molina 15v.

11 La tilmatli era una manta o vestidura hecha de fibra de palma de maguey para las clases bajas y de algodón exclusivamente para los sefiores. Durán, tomo II, cap. XXVI, pp. 211-213 y Rief Anwalt, p. 27.

12 Tezozomoc, p. 52; Durán, cap. IX. p. 83; Acosta, Libro séptimo, Cap. 13, p. 343; Caso, p. 36; Valero, 1991, Cap. IV, p. 90.

13 Sahagún, Lib. VIII, Cap. II.

14 Chimalpahin, Séptima relación, p. 267.

15 Barlow, p. 312.

16 Tezozomoc, p. 172.

17 Archivo General de la Nación. Tierras, 1586; Códice Garcia Granados, Valle, "Códice Tlatelolco".

18 Ventura Beleña, Tomo II, p. 190. número 45.

19 Archivo General de la Nación, Tierras, tomo 3, 1592, Exp. 1; Fernández de Recas, p. 8; Códice Garcia Granados.

20 Se ha dicho que dicha cédula está mal fechada, o bien que fue falsificada, porque el año de 1523 cuando supuestamente se dicta, queda desfasado de la época en que don Diego pudo haber recibido dichas mercedes. Barlow, p. 311.

21 Ventura Belefia, tomo Y, foja 28.

22 Závala, p. 112-143.

23 Borah, pp. 51, 52.

24 Marcos Matías Alonso, pp. 177-210.

25 Joaquín Galarza, p. 87.

26 Marcos Matías Alonso, op. cit.

27 Antonio Periafiel, p. 11. 
28 Idem.

29 Comunicación personal del Párroco de San Juan Ixhuarepec, R.P. Alejandro Pérez Castro, el 13 de agosto de 1994.

30 Vasco de Puga, Carta del 18 de agosto de 1556, foja 188v. y del 19 de enero de 1560 fojas $288 \mathrm{r}$. y 208v. Zorita, pp. 97-101. Borah, pp. 196-197. Chevalier, p. 232.

31 Zorita, pp. 97-101.

32 Zorita pp. 93, 95, 98, 138, 154.

33 "Carta de Fray Bartolomé de las Casas, Obispo de Chiapa al Principe don Felipe sobre asuntos de su diócesis y otros generales", en Cartas de Indias, pp. 28-37 y "Carta del doctor Diego Quixada, alcalde mayor de Mérida de Yucatán a S.M. en Cartas de Indias, p. 370.

34 Vasco de Puga, foja 189v.

35 Zorita, p. 145.

36 Zorita, pp. 54, 94, 97. Borah, p. 40-50. Závala, p. 133.

\section{OBRAS CONSULTADAS}

ACOSTA, JOSEPH DE, Historia natural y moral de las Indias, México, Fondo de Cultura Económica, la, reimpresión, 1979.

ALFONSO, MARCOS MATIAS, "La antropometrla indígena en las medidas de longitud" en Coloquio de documentos pictogrdficos de tradición Nábuath México, U.N.A.M., 1989, pp. 177210.

ARCHIVO GENERAL DE LA NACION, Ramo de tierras: 1586, 1592, tomo 3, exp. 1.

BARLOW, ROBERT H., Tlatelolco, rival de Tecnochtitlán, México, I.N.A.H/U.D.L.A., 1987.

BORAH, WOODROW, El Juzgado General de Indios en la Nueva España. México, Fondo de Cultura Económica, Primera edición en espafiol, 1985.

CASO, ALFONSO, "La tenencia de la tierra entre los antiguos mexicanos". Sobretiro de la Memoria de El Colegio Nacional, t. IV, núm. 2, 1959, México, 1960.

CASTILLO FARRERA, VICTOR M. Estructura económica de la sociedad mexica segín las fuentes documentales. México, U.N.A.M., 1972.

CLAVIJERO; FRANCISCO XAVIER, Historia antigua de México, México Porrúa, Ga. edición, 1979.

CODICE TECHIALOYAN GARCIA GRANADOS, Toluca, Gobierno del Estado de México Sección de Finanzas y Planeación, 1992.

CÓDICE TLATELOLCO, Estudio preliminar de Perla Valle, México, I.N.A.H. / BUAP, 1994.

CHEVALIER, FRANCOIS, La formación de los latifundios en México, México, F.C.E.

México, Segunda edición, 1976.

CHIMALPAHIN CUAHTLEHUANITZIN, FRANCISCO DE SAN ANTON MUÑON, Relaciones originales de Chalco Amequemecan, México, Fondo de Cultura Económica, 1965.

DURÁN FRAY DIEGO DE, Historia de las indias de Nueva España e islas de la Tierra. México, Porrúa, 1967, 2 tomos.

FERNÁNDEZ DE RECAS, GUILLERMO, Cacicazgos y nobiliario indigena de la Nueva España. México, Biblioteca Nacional de México, Instituto Bio-Bibliográfico Mexicano, 1961. 
GALARZA, JOAQUIN, Estudios de escritura indigena azteca nabuatl. México, A.G.N./CEMCA, 1980.

GIBSON, CHARLES, Los aztecas bajo el dominio español (1519-1810), México, Siglo XXI Editores,
1960 .

GLASS, JOHN B. "A Survey of native middle american pictorial manuscripts" en: Handbook of middle american indians, guide to etnohistorical sources, part three, Univesity of Texas, Austin, 1975.

MOLINA, FRAY ALONSO DE, Vocabulario en lengua castellana y mexicana y castellana, estudio preliminar de Miguel León Portilla, México, Porrúa, 1977.

MORALES PADRON, FRANCISCO, Teoria y leyes de la conquista, Madrid, Ediciones de Cultura Hispánica, a 1979.

PALACIOS, PRUDENCIO ANTONIO DE, Notas a la recopilación de leyes de Indias, México, U.N.A.M., 1979.

PEŃAFIEL, ANTONIO, Titulos de Santa Isabel Tola, Manuscrito americano número 4 de la Biblioteca Real de Berlín, copiado en Febrero de 1890 en Colección de Documentos para la bistoria mexicana, parte 1 , México $v$.

RIEFF ANWALT, PATRICIA, Indian clothing befor cortes, mesoamerican costumes from the Codices, University of Oldahoma Press, 1990.

SAHAGÚN, FRAY BERNARDINO DE, Historia general de las cosas de la Nueva España, México, 4a. Edición, Porrúa, 1979.

SIMEON, REMI, Diccionario de Nabuath México, Siglo XXI, editores, 1977.

TAYLOR, WILLIAM B. Landlord and peasant in colonial Oaxaca, Stanford, 1973.

Embriaguez, bomicidio y rebelión en las poblaciones coloniales mexicanas, México, F.C.E., la. edición en espafiol, 1987.

TEZOZOMOC. D. HERNÁNDO ALVARADO, Crónica mexicana, anotada por el Sr. Lic. D. Manuel Orozco y Berra y precedida del Códice Ramtrez, México, Porrúa, 3a. edición, 1980.

VALERO DE GARCIA LASCURAIN, ANA RITA. Solares y conquistadores. Orfgenes de la propiedad en la ciudad de México. México I.N.A.H., 1991.

VALERO DE GARCIA LASCURAIN, ESTEBAN SANCHEZ DE TAGLE Y SERGIO B. MARTÍNEZ, Padrón de frentes o historia del primer impuesto predial, U.N.A.M., (en prensa).

VALLE, PERLA, Códice Tlatelolco, Estudio preliminar, México, I.N.A.H./BUAP, 1994.

VAZQUEZ, GENARO V., Doctrina y realidades de la Legislación para Indios, México, Departamento de Asuntos Indigenas, Primer Congreso Indigenista Interamericano, 1940.

VENTURA BELENA, EUSEBIO, Recopilacion sumaria de todos los autos acordados de la Real Audiencia y Sala del Crimen de esta Nueva España, México, 1781, edición facsimilar de la Universidad Nacional Autónoma de México, 1981, 2 tomos.

ZAVALA, SILVIO, La politica indigenista en México, México, Instituto Nacional Indigenista, Colección SEP/INI, 20 tomo Y, 1973.

ZORITA, ALONSO DE, Breve relación de los sefiores de la Nueva España, varias relaciones antiguas, Siglo XVI, Nueva Colección de documentos para la historia de México, México s/f, editorial Chávez Hayhoe. 